\title{
Costs and clinical consequences of suboptimal atrial fibrillation management
}

This article was published in the following Dove Press journal:

Clinico Economics and Outcomes Research

24 March 2012

Number of times this article has been viewed

\section{Steven N Singh}

Department of Cardiology, Veterans Affairs Medical Center, Washington, DC, USA
Correspondence: Steven N Singh Department of Cardiology, Veterans Affairs Medical Center, 50 Irving St NW, Washington, DC 20422, USA

Tel +I 2027458 II 5

Email steve.singh@med.va.gov
Abstract: Atrial fibrillation (AF) places a considerable burden on the US health care system, society, and individual patients due to its associated morbidity, mortality, and reduced healthrelated quality of life. AF increases the risk of stroke, which often results in lengthy hospital stays, increased disability, and long-term care, all of which impact medical costs. An expected increase in the prevalence of AF and incidence of AF-related stroke underscores the need for optimal management of this disorder. Although AF treatment strategies have been proven effective in clinical trials, data show that patients still receive suboptimal treatment. Adherence to $\mathrm{AF}$ treatment guidelines will help to optimize treatment and reduce costs due to $\mathrm{AF}$-associated events; new treatments for AF show promise for future reductions in disease and cost burden due to improved tolerability profiles. Additional research is necessary to compare treatment costs and outcomes of new versus existing agents; an immediate effort to optimize treatment based on existing evidence and guidelines is critical to reducing the burden of AF.

Keywords: atrial fibrillation, pharmacoeconomics, stroke, health-related quality of life

\section{Introduction}

Atrial fibrillation (AF), the ineffective and uncoordinated contraction of the atria, is the most common sustained heart rhythm disturbance seen in clinical practice. ${ }^{1,2}$ An estimated 3.03 million Americans had AF in 2005, and the prevalence is expected to rise to 7.56 million by $2050 .{ }^{3}$ Between 1985 and 1999, the number of hospitalizations with AF as a principal diagnosis increased by $144 \%$ according to the National Hospital Discharge Survey. ${ }^{4}$ These numbers are probably even greater, since arrhythmias represented $10.6 \%$ of patients with a principal diagnosis related to the circulatory system. ${ }^{5}$ Research demonstrates a potential link between AF and atherosclerotic vascular disease, hypertension, chronic inflammation, and metabolic syndrome. ${ }^{6} \mathrm{AF}$ is also associated with substantial morbidity (stroke, heart failure), mortality, and poor health-related quality of life. ${ }^{7-14}$ Based on these issues, AF imposes a considerable cost burden on the patient, the health care system, and society. ${ }^{15-17}$

AF treatment is complex. Comprehensive management of the patient with AF requires a multifaceted approach directed at first identifying any underlying, reversible, treatable causes, ${ }^{18}$ and then controlling symptoms and protecting the patient from central and peripheral embolism. ${ }^{19,20}$ The American College of Cardiology Foundation, American Heart Association, and Heart Rhythm Society (ACCF/AHA/HRS) task force recommend that AF management involve three nonmutually exclusive objectives: rate control, prevention of thromboembolism, and correction of the rhythm disturbance (Figure 1). ${ }^{19}$ The initial management decision is either a rate-control or rhythm-control strategy. 


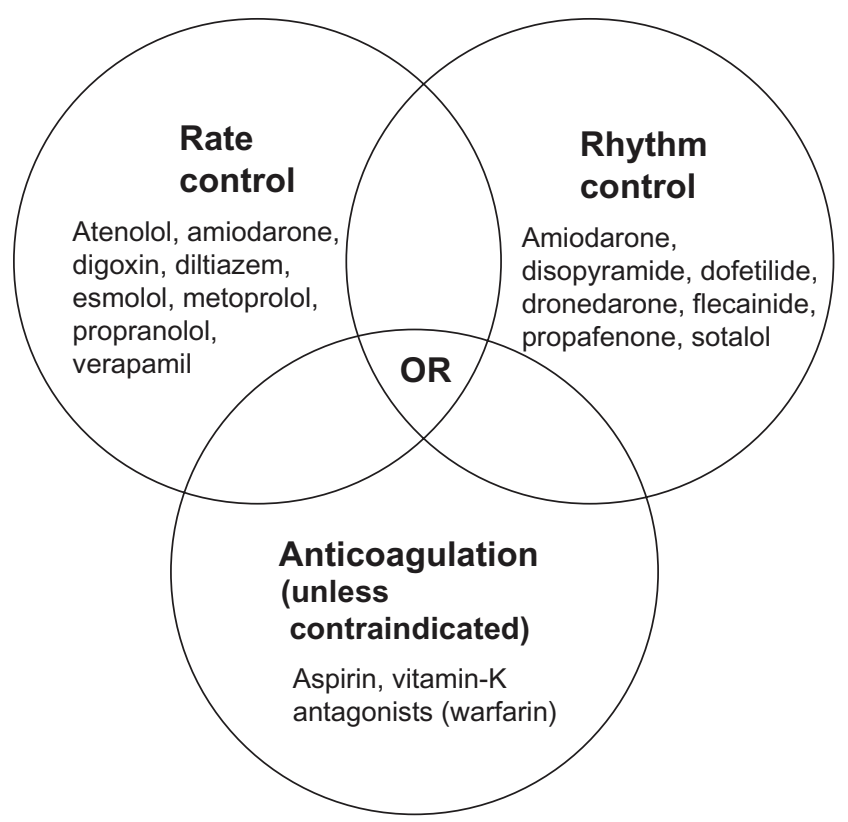

Figure I AF treatment. Drugs are listed alphabetically. ${ }^{19}$ Abbreviation: $A F$, atrial fibrillation.

Using the rate-control strategy, the ventricular rate is controlled with no commitment to restore or maintain sinus rhythm, unlike the rhythm-control strategy, which attempts restoration and maintenance of sinus rhythm. ${ }^{19}$

Anticoagulation therapy is to be considered regardless of which rate or rhythm control therapy is prescribed, because current agents used for rate and rhythm control do not reduce stroke risk and cannot be substituted for antithrombotic treatment. $^{21,22}$ The $\mathrm{CHADS}_{2}$ scoring system, which utilizes age and comorbid conditions to stratify a patient's stroke risk, is recommended to aid in the decision to use antithrombotic therapy (Table 1) ${ }^{19,23}$ Despite the guidelines, AF may be managed suboptimally due to the complexity of treatment. It has been shown that compliance with some antiarrhythmic agents is poor and patients who discontinue treatment are unlikely to restart therapy. ${ }^{24}$ Suboptimal management of AF could result in a delay in reverting the patient to normal sinus rhythm, which in turn could promote atrial remodeling, making future sinus rhythm maintenance difficult. ${ }^{25}$ This article discusses the clinical consequences and associated costs of suboptimal management of AF in the United States (US), as well as treatment strategies that may reduce the burden of $\mathrm{AF}$ and improve patient outcomes.

\section{Overall economic burden of AF in the US}

Although there are numerous cost-comparison studies of different AF treatments, there are few US-based direct cost
Table I $\mathrm{CHADS}_{2}$ index stroke risk in patients with nonvalvular AF not treated with anticoagulation and recommended antithrombotic therapy by risk factors ${ }^{a}$

\begin{tabular}{ll}
\hline CHADS $_{2}$ risk criteria & Score \\
\hline Prior stroke or TIA & 2 \\
Age $>75$ years & I \\
Hypertension & I \\
Diabetes mellitus & Recommended therapy \\
Heart failure & Aspirin, 8 I to 325 mg daily \\
Risk category & Aspirin, 8 I to 325 mg daily, or warfarin \\
\hline No risk factors & (INR 2.0 to 3.0, target 2.5) \\
I moderate risk factor & Warfarin (INR 2.0 to 3.0, target 2.5) \\
Any high risk factor or $>$ I & \\
moderate risk factor &
\end{tabular}

Notes: ${ }^{a}$ Guideline-based therapy recommendations include consideration of $\mathrm{CHADS}_{2}$ and other risk factors; 'bmoderate risk factors: all $\mathrm{CHADS}_{2}$ risk factors with a score of I as well as left ventricular ejection fraction $\leq 35 \%$; high risk factors: prior stroke, TIA, or embolism; mitral stenosis; prosthetic heart valve (if mechanical valve, target INR > 2.5).

Copyright ${ }^{\oplus} 201$ I, Elsevier. Adapted with permission from Fuster V, Ryden LE, Cannom DS, et al. 20I I ACCF/AHA/HRS Focused Updates Incorporated Into the ACC/AHA/ ESC 2006 Guidelines for the Management of Patients With Atrial Fibrillation A Report of the American College of Cardiology Foundation/American Heart Association Task Force on Practice Guidelines Developed in partnership with the European Society of Cardiology and in collaboration with the European Heart Rhythm Association and the Heart Rhythm Society. J Am Coll Cardiol. 201 I;57(I I):el01-e 198. ${ }^{19}$

Abbreviations: TIA, transient ischemic attack; INR, international normalized ratio.

assessments of AF treatments. A recent national survey estimated that direct medical costs were $73 \%$ higher in patients with AF compared with matched control subjects, representing a net incremental cost of $\$ 8705$ per patient per year and a national incremental cost between $\$ 6.0$ and $\$ 26.0$ billion (2008 US dollars [USD]). ${ }^{26}$ A 2001 study found that approximately 234,000 hospital outpatient department visits, 276,000 emergency room visits, 350,000 hospitalizations, and 5 million office visits were attributable annually to AF. ${ }^{15}$ It has been shown that in the year following index hospitalization, $12.5 \%$ of chronic AF patients and $10.1 \%$ of newly diagnosed AF patients are readmitted for $\mathrm{AF}^{27}$ The total annual medical cost for the treatment of AF in the inpatient, emergency department, and hospital outpatient settings was estimated at $\$ 6.65$ billion (2005 USD; inflation-adjusted to 7.71 billion 2011 USD) (Figure 2), and is likely an underestimate as costs for longterm anticoagulation, stroke prevention, inpatient drugs, and hospital-based physician services were not included. ${ }^{15}$ This assessment included billed hospital charges and costs of procedures for which AF was the principal discharge diagnosis ( $\$ 2.93$ billion), incremental inpatient costs due to $\mathrm{AF}$ as a comorbid diagnosis ( $\$ 1.95$ billion), and physician fees, drugs, procedures, and facility costs for ambulatory/ outpatient treatment of AF ( $\$ 1.76$ billion). ${ }^{15}$ 


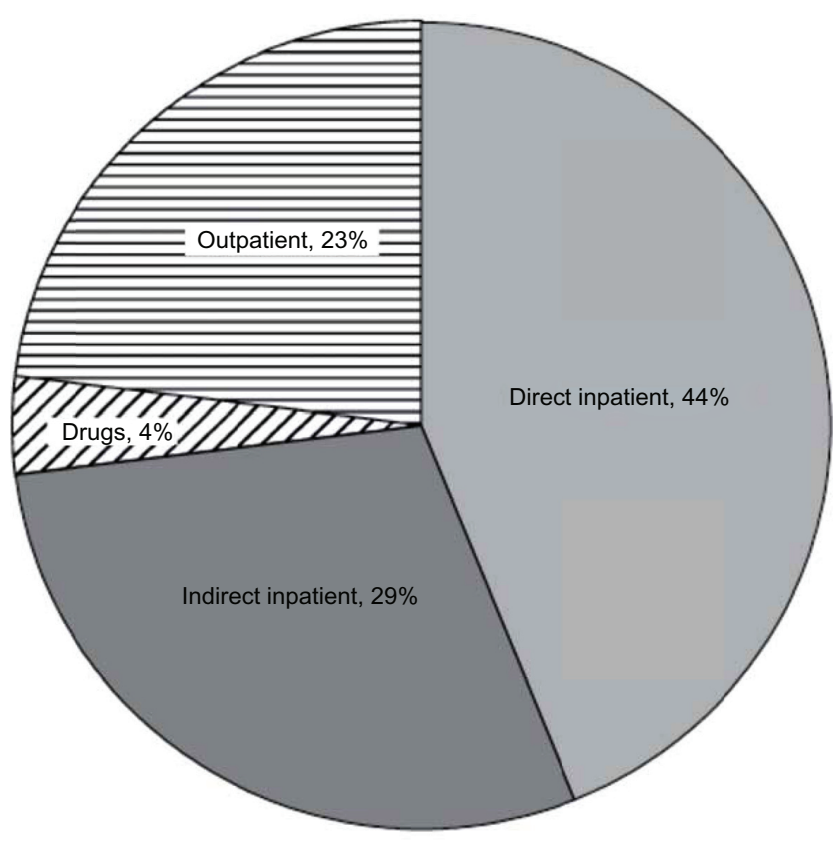

Figure 2 Distribution of total medical costs for treating AF in the United States (2005).

Copyright $^{\odot}$ 2006, John Wiley and Sons. Reprinted with permission from Coyne KS Paramore C, Grandy S, Mercader M, Reynolds M, Zimetbaum P. Assessing the direct costs of treating nonvalvular atrial fibrillation in the United States. Value Health. 2006;9(5):348-356..$^{15}$

Abbreviation: $\mathrm{AF}$, atrial fibrillation

One study estimated the direct and indirect costs of AF (2002 USD) in a privately insured US population aged $<65$ years. The direct annual cost of AF was $\$ 15,553$ per patient compared with $\$ 3204$ for enrollees without AF. These costs were adjusted to $\$ 19,575$ and $\$ 4809$ in 2011 USD. ${ }^{16}$ Indirect costs (ie, disability claims and absenteeism) were \$2134 higher annually for AF patients compared with enrollees without AF (\$2847 [\$3583 2011 USD] vs \$713 [\$897 2011 USD], respectively). Regarding patients aged $>65$ years, a Medicare database study found that the adjusted mean incremental treatment cost of AF was \$14,199 (2004 USD; \$17,019 2011 USD) in patients diagnosed with AF and followed for 1 year. ${ }^{17}$ Some of this cost was attributable to the incidence of stroke and heart failure 1 year after diagnosis. ${ }^{17} \mathrm{In}$ another study, inpatient costs were \$11,307 (2006 USD; \$12,699 2011 USD) and outpatient costs were $\$ 2827$ (\$3175 2011 USD) for primary AF hospitalization; for hospitalized patients with secondary AF, AF-related inpatient costs were $\$ 5181$ (\$5819 2011 USD) and outpatient costs were $\$ 1376$ (\$1545 2011 USD). ${ }^{28}$ Table 2 contains recently published data on direct health care costs attributable to an AF diagnosis, including cost adjustments to 2011 USD (differing costs may reflect variations in study designs and data sets). ${ }^{28-30}$

Inpatient drug initiation and costs of adverse events and adverse-event monitoring significantly add to the overall economic burden of AF treatment. A recent analysis examined the costs associated with initiating sotalol and dofetilide in the inpatient setting. ${ }^{31}$ Treatment guidelines recommend inpatient initiation of dofetilide, while the initiation of sotalol is mandated by the US Food and Drug Administration (FDA), with a recommended minimum hospital stay of 3 days to assess for ventricular proarrhythmia. ${ }^{19,32,33}$ Mean total inpatient costs per patient were $\$ 3278$ in the sotalol group and \$3610 in the dofetilide group (2007 USD; \$3580 and $\$ 39422011$ USD, respectively). The greatest costs were for room and board followed by cardiology/electrocardiograms. ${ }^{31}$ The incidence and cost of suspected adverse events and adverse-event monitoring during AF rhythm control and/or rate-control therapy was also high. ${ }^{34}$ Overall, $50.1 \%$ of treated patients had a suspected adverse event and/or function test for adverse-event monitoring (45.5\% with rate control, $53.5 \%$ with rhythm control, and $61.2 \%$ with combined rhythm/rate control). The mean cost of adverse events and adverse-event monitoring among treated patients was $\$ 3089$ per patient (2006 USD; \$3469 2011 USD). ${ }^{34}$

\section{Cost of stroke in patients with AF}

Stroke is a leading cause of death in the world and a leading cause of morbidity in adults aged $>60$ years. $^{35}$

Table 2 Recently published AF health care costs

\begin{tabular}{|c|c|c|c|c|c|}
\hline $\begin{array}{l}\text { Study } \\
\text { (USD) }\end{array}$ & Diagnosis & Patient population & $\begin{array}{l}\text { Inpatient } \\
\text { costs }^{\mathrm{a}}\end{array}$ & $\begin{array}{l}\text { Outpatient } \\
\text { costs }^{a}\end{array}$ & $\begin{array}{l}\text { Total AF-related } \\
\text { costs }^{\mathrm{a}}\end{array}$ \\
\hline $\begin{array}{l}\text { Patel }^{29} \\
\text { (2006 USD) }\end{array}$ & $\begin{array}{l}\text { Nontransient } \\
\text { AF/AFL }\end{array}$ & $\begin{array}{l}32,905 \text { patients in US claims database } \\
\text { (mean age } 74 \text { years, } 56 \% \text { male, I/04-12/07) }\end{array}$ & $\$ 22,582(\$ 25,362)$ & $\$ 15,688(\$ 17,620)$ & $\$ 38,270(\$ 42,982)$ \\
\hline \multirow[t]{2}{*}{$\begin{array}{l}\mathrm{Kim}^{28} \\
\text { (2006 USD) }\end{array}$} & Primary AF & $\begin{array}{l}35,255 \text { patients in US claims database } \\
\text { (mean age } 64 \text { years, } 65 \% \text { male, I/05-12/06) }\end{array}$ & $\$ 11,307(\$ 12,699)$ & $\$ 2827(\$ 3175)$ & $\$ 14,134(\$ 15,874)$ \\
\hline & Secondary AF & & $\$ 5181$ (\$5819) & $\$ 1376(\$ 1545)$ & $\$ 6557(\$ 7364)$ \\
\hline $\begin{array}{l}\mathrm{Kim}^{30} \\
(2007 \text { USD) }\end{array}$ & $\mathrm{AF}$ & $\begin{array}{l}3605 \text { patients in US claims database } \\
\text { (mean age } 63 \text { years, } 69 \% \text { male, } 4 / 0 \mathrm{I}-3 / 07 \text { ) }\end{array}$ & $\$ 3872(\$ 4228)$ & $\$ 2293(\$ 2504)$ & $\$ 6165(\$ 6732)$ \\
\hline
\end{tabular}

Note: ${ }^{\text {aC }}$ osts inflation-adjusted to 20I I USD using the Bureau of Labor Statistics CPI inflation calculator.

Abbreviations: AF, atrial fibrillation; AFL, atrial flutter; USD, United States dollars. 
$\mathrm{AF}$ independently increases the risk of ischemic stroke by four- to fivefold. ${ }^{36}$ In the absence of antithrombotic therapy, the annual risk of stroke in patients with AF (with risk factors including history of hypertension, diabetes, and history of prior stroke/transient ischemic attack [TIA]) is $4.9 \%$ in patients aged $<65$ years and $8.1 \%$ in patients aged $>75$ years. ${ }^{37}$ Because the prevalence of AF increases with age and older age confers an increased risk of stroke, the proportion of strokes attributable to AF increases with age. ${ }^{37}$

Stroke is associated with substantial inpatient and longterm costs. ${ }^{38} \mathrm{~A}$ review of published data on AF prevalence found that survivors of AF-related stroke were more likely to have longer hospital stays, disability, and need for longterm care, all of which increase health care costs. ${ }^{39} \mathrm{~A}$ review of 14 studies found that patients with AF-related stroke had worse outcomes than patients with non-AF-related stroke, including higher mortality, severity, recurrence, functional impairment, and dependency ${ }^{40} \mathrm{~A}$ retrospective chart review showed that patients with AF-associated ischemic stroke were 2.23 times more likely to be bedridden than patients who had strokes from other causes..$^{41}$ Importantly, previously diagnosed AF patients in this chart review were not receiving therapeutic anticoagulation at the time of their stroke. ${ }^{41}$

A recent retrospective observational cohort study utilized medical and pharmacy claims from a managed care organization to identify continuously benefit-eligible AF patients without prior valvular disease or warfarin use between 2000 and 2002 (costs adjusted to 2004 USD). ${ }^{42}$ All patients were followed for at least 6 months, until plan termination or the end of study follow-up. Stroke risk was assessed using the $\mathrm{CHADS}_{2}$ index. Inpatient and outpatient cost benchmarks were utilized to estimate total direct health care costs (pre- and post-AF index claim). Total direct health care costs were also assessed for patients with TIA, ischemic stroke (IS), and major bleed (MB). Pre- versus post-AF diagnosis total direct health care costs were $\$ 412$ and $\$ 1235$ per member per month ( $\mathrm{pmpm}$ ), respectively (\$494 and $\$ 14802011$ USD, respectively). Of the 448 (12\%) patients with a TIA, IS, or MB, pmpm costs post-AF diagnosis ranged from \$2235 to \$3135 (\$2679-\$3758 2011 USD) correlating with $\mathrm{CHADS}_{2}$ stroke-risk status and exposure to warfarin. Total cohort pmpm costs pre- and post-event increased 24\% from $\$ 3447$ to $\$ 4262$ (\$4132-\$5109 2011 USD). ${ }^{42}$

\section{Cost benefits of optimal anticoagulation}

In the US, increasing rates of AF-related stroke due to the aging population will come at a high cost to society given the overlap between AF-attributable stroke and the age of Medicare eligibility. The need for optimal anticoagulation was demonstrated in a pooled analysis of five large, randomized, controlled $\mathrm{AF}$ antithrombotic trials, which showed that warfarin reduced the frequency of all strokes by $68 \%$ (95\% confidence interval [CI]: 50\%-79\%); the efficacy of aspirin was less consistent. ${ }^{37} \mathrm{~A}$ conservative economic model estimated a Medicare saving of $\$ 1.14$ billion annually (2003 USD; \$1.4 billion 2011 USD) through maintaining patients eligible for anticoagulation on therapeutic doses of warfarin ${ }^{43}$ Depending on the study population, anticoagulant therapy has been shown to decrease the risk of stroke by $42 \%$ to $86 \%{ }^{44}$

Although several randomized clinical trials have documented the benefits of warfarin in preventing AF-related stroke, a growing body of evidence indicates that anticoagulants are routinely underutilized for stroke prevention in patients with $\mathrm{AF}^{45,46}$ It has been estimated that half of the patients receiving warfarin do not receive the appropriate anticoagulant therapy. ${ }^{44}$ Anticoagulant therapy with warfarin has a narrow therapeutic index requiring coagulation monitoring by a physician or, in some cases, pharmacists and nurses; ${ }^{47,48}$ this requirement, along with the inherent properties of warfarin related to its bleeding risk, may contribute to its low levels of utilization. ${ }^{45} \mathrm{~A}$ comparative study between usual medical care and a clinical pharmacistrun anticoagulation clinic showed that pharmacist supervision improved anticoagulation control, reduced bleeding and thromboembolic event rates, and saved \$162,058 per 100 patients annually (1998 USD; \$225,112 2011 USD) in reduced hospitalizations and emergency department visits. ${ }^{49}$ Figure 3 presents a disease model showing the effects of suboptimal versus optimal oral anticoagulation on stroke rates. The economic model considers a stable population of patients with AF, such as that which might be found in a managed care organization or a state's Medicare group; it allows for movement of individuals with AF in and out of the population during the course of a year. Scenarios are created (eg, "if half of all those who currently do not receive anticoagulation were to receive well-controlled warfarin") to represent the current situation in the population of interest compared with other potential scenarios of care. According to this model, stroke rates and associated costs could decrease dramatically if $50 \%$ of warfarin-eligible patients were optimally coagulated. Approximately 1.265 million patients currently not receiving prophylaxis suffer over 58,000 strokes annually. If half of those not receiving warfarin were optimally anticoagulated, approximately 19,000 strokes would be prevented. ${ }^{43}$ 
A

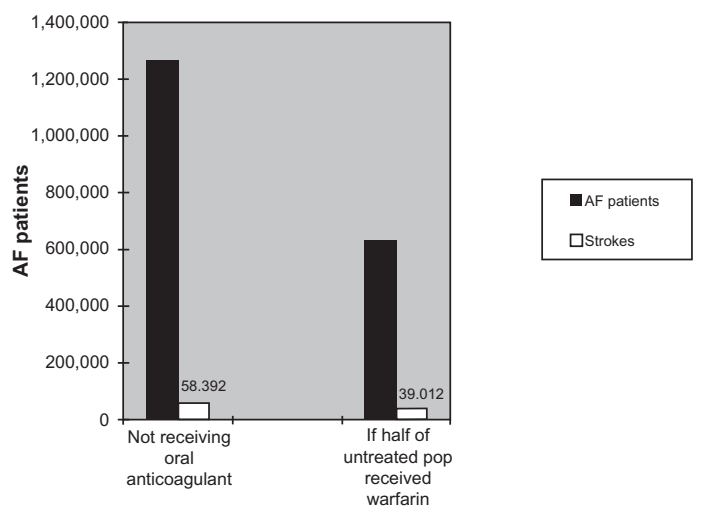

B

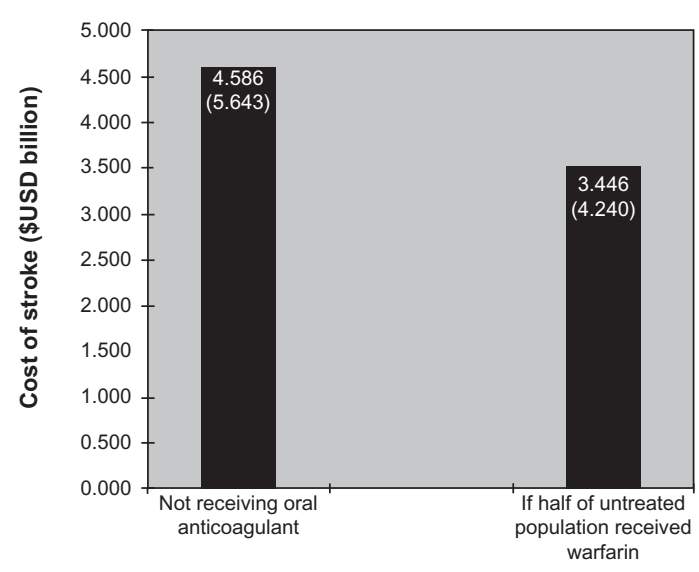

Figure 3 Model results: (A) reductions in AF-related stroke based upon half of untreated patients receiving warfarin and (B) cost of stroke. ${ }^{43}$ The economic model considers a stable population of patients with AF, such as that which might be found in a managed care organization or a state's Medicare group.

Notes: Cost estimates were based on published epidemiologic data and 2003 Medicare cost data. Values in parentheses are inflation-adjusted costs to 2011 US dollars using the Bureau of Labor Statistics CPI inflation calculator.

Abbreviation: AF, atrial fibrillation.

Warfarin therapy is monitored to ensure that patients remain within the target international normalized ratio (INR) range of 2.0 to 3.0. Studies of the quality of anticoagulation management in patients with AF found that up to $60 \%$ of patients receiving warfarin have INR outside the recommended therapeutic target range. ${ }^{50-52}$ It is likely that these studies can be generalized to the US population as they included AF patients in a range of settings (emergency department, longterm care, and community); one can therefore conclude that the majority of patients with an AF diagnosis in the US are not optimally treated with anticoagulant therapies. Such suboptimal therapy places patients at risk for complications and further management expenditures. ${ }^{53}$

One real-world study estimated the cost effectiveness of different warfarin treatment scenarios. ${ }^{53} \mathrm{~A}$ semi-Markov transition model (11 primary health states with four additional states representing temporary discontinuation of therapy) was designed due to the chronic nature of $\mathrm{AF}$ and its treatment and the varying but continuous risk of stroke and hemorrhage. The scenarios included in the model were: (1) perfect warfarin control $(100 \%$ of patients within target INR and following guideline recommendations ${ }^{19,54}$ for ideal treatment goal); (2) trial-like warfarin control (clinical trial conditions; INRs within target $68 \%$ of the time as reported in the Stroke Prevention by ORal Thrombin Inhibitor in atrial Fibrillation [SPORTIF] V trial):55 (3) "real-world" warfarin control (routine clinical practice conditions; INRs within target $48 \%$ of the time based on data from a retrospective study of US outpatient physician practices) $;^{56}$ and (4) real-world prescription (and control) of warfarin, aspirin, or neither for warfarin-eligible patients at moderate-to-high risk of stroke (routine clinical practice conditions, in which a proportion of warfarin-eligible patients were prescribed either aspirin [12\%] or neither warfarin nor aspirin [23\%]). ${ }^{56}$ The total number of primary and recurrent ischemic strokes in a cohort of 1000 patients (age 70 years) was assessed, and the model showed increased numbers of strokes as real-world conditions increased and trial-like management declined. Both clinical and cost outcomes were found to be dependent on the quality of anticoagulation (Table 3).

In another cost-effectiveness semi-Markov decision analysis model of patients with AF, the lifetime cost per patient for anticoagulation using a monitoring service was found to be $\$ 8661$ versus $\$ 10,746$ for usual care (2004 USD; $\$ 10,381$ vs $\$ 12,8802011$ USD). ${ }^{57}$ The model predicted that anticoagulation services improved the effectiveness (measured in quality-adjusted life-years [QALYs]) and reduced costs (estimated at \$2100; \$2517 2011 USD), and was therefore superior to usual care.

In terms of the cost of MB events with warfarin use, a recent database study of warfarin-treated patients with $\mathrm{AF}$ found that MB events associated with warfarin therapy, although nearly twice as costly compared with patients without MB events, were relatively rare; among 47,437 total patients, only $194(0.4 \%)$ had intracranial MB events and 919 (1.9\%) experienced gastrointestinal MB events. ${ }^{58}$

In addition to warfarin and other anticoagulants (eg, unfractionated heparin and low-molecular-weight heparin), direct thrombin inhibitors represent a newer class of anticoagulants. ${ }^{59}$ Newer antithrombotic agents include rivaroxaban, apixaban, and dabigatran, which are selective for specific coagulation factors such as factor Xa and thrombin. ${ }^{60-62}$ Advantages shared by these newer anticoagulants over existing antithrombotic agents consist of selective 
Table 3 Results of a cost-effectiveness model predicting clinical trial versus "real-world" warfarin usage for AF-related stroke prevention $^{53}$

\begin{tabular}{llll}
\hline & $\begin{array}{l}\text { Base case } \\
\text { total medical costs/patient } \\
(\mathbf{2 0 0 6} \text { USD/20 I I USD })\end{array}$ & $\begin{array}{l}\text { Base case: } \\
\text { total \# primary and } \\
\text { recurrent IS }\end{array}$ & $\begin{array}{l}\text { Modelc: } \\
\text { total \# primary } \\
\text { and recurrent IS }\end{array}$ \\
\hline Scenario I: perfect warfarin control & $\$ 68,039 / \$ 76,416$ & 626 & 503 \\
Scenario 2: clinical trial-like warfarin control & $\$ 77,764 / \$ 87,338$ & 832 & 737 \\
Scenario 3: real-world warfarin control & $\$ 84,518 / \$ 94,924$ & 984 & 909 \\
Scenario 4: real-world warfarin, aspirin, or neither & $\$ 87,248 / \$ 97,990$ & $117 \mid$ & 1120 \\
\hline
\end{tabular}

Notes: ${ }^{a}$ Base case: $\mathrm{N}=1000$, age 70 , moderate-to-high risk of stroke, followed for remaining lifetime; ${ }^{\mathrm{b}}$ costs inflation-adjusted to $20 \mathrm{I}$ I USD using the Bureau of Labor Statistics CPI inflation calculator; ' perfect warfarin adherence.

Abbreviations: IS, ischemic stroke; USD, United States dollars.

targeting for a single coagulation factor, rapid onset of action, fewer drug interactions, and no required dosage adjustment according to patient age, gender, body weight, or mild renal impairment. ${ }^{62}$ Clinical trials with these new anticoagulants in patients with $\mathrm{AF}$ include ROCKET-AF (rivaroxaban vs warfarin), ARISTOTLE (apixaban vs warfarin) and AVERROES (apixaban vs aspirin in patients unsuitable for warfarin). The ROCKET-AF trial showed that rivaroxaban was noninferior to warfarin with regard to stroke or systemic embolism in patients with nonvalvular AF. ${ }^{63}$ Rivaroxaban is approved by the FDA for the prevention of stroke in patients with nonvalvular AF. ${ }^{64}$ In the AVERROES study, apixaban reduced the risk of stroke or systemic embolism without significantly increasing major bleeding or intracranial hemorrhage, ${ }^{65}$ while the ARISTOTLE study demonstrated that apixaban was superior to warfarin in preventing stroke or systemic embolism. ${ }^{66}$ An important limitation to the use of these agents is the lack of readily available reversal agents or antidotes.

Dabigatran is a novel oral direct thrombin inhibitor that is approved in the US (October 2010) to reduce the risk of stroke and systemic embolism in patients with $\mathrm{AF}^{67}$ In the Randomized Evaluation of Long-Term Anticoagulation Therapy (RE-LY) trial, two fixed doses of dabigatran (110 and $150 \mathrm{mg}$, administered in a blinded fashion) were compared with open-label use of warfarin in patients with AF and an increased risk for stroke. ${ }^{68,69}$ After a follow-up of 2 years, the primary endpoint of stroke or systemic embolism occurred in 182 patients in the dabigatran $110 \mathrm{mg}$ group (1.53\%/year), 134 patients in the dabigatran $150 \mathrm{mg}$ group (1.11\%/year), and 199 patients in the warfarin group $(1.69 \% /$ year). Both dabigatran doses were found to be noninferior to warfarin $(P<0.001)$, and the dabigatran $150-\mathrm{mg}$ dose was found to be superior to warfarin $(P<0.001)$. Hemorrhagic stroke rates were $0.38 \%$ per year in the warfarin group versus $0.12 \%$ per year in the dabigatran $110 \mathrm{mg}$ group and $0.10 \%$ per year in the dabigatran $150 \mathrm{mg}$ group $(P<0.001$, both comparisons). This decrease in the number of strokes with dabigatran may decrease the costs and economic burden associated with stroke. The 2011 ACCF/AHA/HRS guidelines recommend dabigatran as an alternative to warfarin for the prevention of stroke and systemic thromboembolism in patients who have paroxysmal to permanent $\mathrm{AF}$ and risk factors for stroke/systemic embolization and who do not have a prosthetic heart valve, hemodynamically significant valve disease, severe renal failure, or advanced liver disease..$^{70}$

\section{Cost effectiveness of treatment strategies for AF}

The Fibrillation Registry Assessing Costs, Therapies, Adverse Events, and Lifestyle (FRACTAL) study showed that patients with $\mathrm{AF}$ who are managed with cardioversion and pharmacotherapy incur AF- and cardiovascularrelated health care costs of $\$ 4000$ to $\$ 5000$ per year (2002 USD; \$5034-\$62932011 USD). ${ }^{71}$ AF-related health care costs averaged $\$ 4700$ (\$5915 2011 USD) per patient per year during the first few years following diagnosis, ${ }^{71}$ but subsequent annual costs varied greatly according to the AF clinical course, with hospital care contributing the largest and most variable component of total cost. Among patients with recurrent $\mathrm{AF}$, the frequency of recurrence was strongly associated with higher resource utilization, with each recurrence increasing annual costs by an average of \$1600 (2002 USD; \$2014 2011 USD). ${ }^{71}$ Several recent studies comparing rate and rhythm control strategies have found no meaningful differences in terms of mortality from cardiovascular causes and stroke. ${ }^{8,21,72-75}$ Additionally, drivers of cost in patients with $\mathrm{AF}$ are not fully elucidated.

A post-hoc cost-effectiveness analysis from the Atrial Fibrillation Follow-Up Investigation of Rhythm Management (AFFIRM) study was published shortly after the FRACTAL study and demonstrated that patients randomized to pharmacologic rate control had less resource utilization and lower costs than patients randomized to rhythm control 
(cost savings range, \$2189-\$5481 per patient, 2002 USD; \$2755-\$6898 2011 USD). ${ }^{76}$ Another post-hoc analysis of AFFIRM clinical treatment data suggested that the benefits of rhythm control may have been offset by the adverse effects of antiarrhythmic therapy, specifically amiodarone, which was used for rhythm control in the study. ${ }^{77}$ Whether these AFFIRM cost data would be affected if different antiarrhythmic agents (with better adverse-effect profiles than amiodarone) were analyzed in the model is unknown; however, as the adverse effects had considerable influence over the cost model, cost data can be expected to be affected. ${ }^{77}$

Newer anticoagulants and antiarrhythmic agents may present cost savings compared with older treatments. In an analysis including patients aged $\geq 65$ years with AF who were at increased risk of stroke, dabigatran was shown to be a cost-effective alternative to warfarin. ${ }^{78}$ The analysis estimated a cost of $\$ 45,372$ per QALY (2008 USD; \$47,715 2011 USD) gained with high-dose dabigatran (150 mg twice daily) compared with warfarin. ${ }^{78}$ Another study compared the cost-effectiveness of dabigatran $150 \mathrm{mg}$ twice daily with warfarin, employing a Markov decision-analysis model in a hypothetical cohort of 70-year-old patients with $\mathrm{AF}$ and a cost-effectiveness threshold of \$50,000/QALY. ${ }^{79}$ The analysis found dabigatran to be cost-effective in AF populations at high risk of hemorrhage or stroke $\left(\mathrm{CHADS}_{2}\right.$ score $\geq 3$ ) and warfarin to be cost-effective in moderate-risk AF populations (CHADS $_{2}$ score 1 or 2$)$. Dabigatran was cost-effective for patients with a $\mathrm{CHADS}_{2}$ score of 2 only if they were at a high risk of major hemorrhage or had poor INR control with warfarin. ${ }^{79}$ In a separate cost-effectiveness analysis employing a Markov decision-analysis model in a hypothetical cohort of 70-year-old patients with AF and a history of stroke or transient ischemic attack, dabigatran provided 0.36 additional QALYs versus warfarin at a cost of \$9000 (2010 USD; \$9314 2011 USD), yielding an incremental cost-effectiveness ratio of $\$ 25,000$ ( $\$ 25,873$ 2011 USD). However, dabigatran was not cost-effective if its relative risk of stroke compared with warfarin exceeded $0.92 .^{80}$ Lastly, in a cost-effectiveness analysis in the United Kingdom of simulated patients at moderate-to-high risk of stroke with a mean baseline $\mathrm{CHADS}_{2}$ score of 2, dabigatran $150 \mathrm{mg}$ twice daily was associated with positive incremental net benefits versus warfarin, but was unlikely to be costeffective in clinics able to achieve good INR control with warfarin. ${ }^{81}$

Given the $24 \%$ relative reduction in hospitalizations demonstrated with dronedarone use in the A Placebo-Controlled,
Double-Blind, Parallel Arm Trial to Assess the Efficacy of Dronedarone $400 \mathrm{mg}$ bid for the Prevention of Cardiovascular Hospitalization or Death from any Cause in Patients with Atrial Fibrillation/Atrial Flutter (ATHENA) trial, ${ }^{82}$ this agent has the potential to reduce costs in patients with AF. One retrospective study analyzed the incidence and direct costs of ATHENAtype outcomes in 15,552 patients with AF who were covered by Medicare supplemental insurance from 2004 to $2007 .^{83}$ Mean hospitalization cost per patient was \$11,085 (2006 USD; $\$ 12,4502011$ USD). Mean costs per patient varied from \$7476 (mean cost per hospitalization for AF/supraventricular rhythm disorder [primary diagnosis, nonfatal]) to $\$ 37,067$ (mean hospitalization cost per death, cardiovascular transcutaneous intervention procedure, or cardiovascular surgical intervention) (\$8396 to $\$ 41,631$, respectively, 2011 USD) ${ }^{83}$ Novel antiarrhythmic therapies such as dronedarone, with the potential to reduce cardiovascular hospitalizations and mortality in similar patients, could decrease health care costs.

\section{New antiarrhythmic agents for the treatment of AF}

Data demonstrate limited efficacy and partially deleterious adverse-effect profiles for conventional antiarrhythmic agents for $\mathrm{AF}^{84}$ Antiarrhythmic agents that have atrial-selective actions and target multiple ion channels may be more tolerable and free of proarrhythmic effects ${ }^{85} \mathrm{New}$ agents (ie, dronedarone and vernakalant) offer promise in optimizing the management of AF by potentially reducing AF burden and costs through more favorable tolerability profiles.

\section{Dronedarone}

Dronedarone, a noniodinated benzofuran derivative, is a recently (2009) approved multichannel antiarrhythmic agent. Dronedarone is indicated in the US to reduce the risk of hospitalization for $\mathrm{AF}$ in patients in sinus rhythm with a history of paroxysmal or persistent $\mathrm{AF}^{86}$ According to the $2011 \mathrm{ACCF} / \mathrm{AHA} / \mathrm{HRS}$ guidelines, dronedarone is recommended as first-line therapy in patients with AF who have no or minimal heart disease, hypertension without left ventricular hypertrophy, or coronary heart disease (class IIa recommendation).$^{70}$ In the ATHENA trial, dronedarone demonstrated a significant risk reduction $(24 \%, P<0.001)$ in hospitalizations due to cardiovascular events or deaths from any cause compared with placebo in patients with paroxysmal or persistent AF/AFL.$^{82}$ In an analysis of stroke in the ATHENA trial, dronedarone reduced the risk of 
stroke from $1.8 \%$ per year to $1.2 \%$ per year $(P=0.027) .{ }^{87} \mathrm{In}$ the Efficacy and Safety of Dronedarone for the Control of Ventricular Rate During Atrial Fibrillation (ERATO) study, dronedarone was found to control ventricular rate in patients diagnosed with permanent $\mathrm{AF}$ already treated with standard therapies. ${ }^{88}$

Dronedarone was demonstrated to be effective in maintaining sinus rhythm in The European Trial in Atrial Fibrillation or Flutter Patients Receiving Dronedarone for the Maintenance of Sinus Rhythm (EURIDIS) study and the American-Australian-African Trial with Dronedarone in Atrial Fibrillation or Flutter Patients for the Maintenance of Sinus Rhythm (ADONIS) study. ${ }^{89}$ The most common adverse events seen with dronedarone include gastrointestinal problems including diarrhea, nausea, and abdominal pain. ${ }^{82,88-}$ ${ }^{91}$ Dronedarone is contraindicated in patients with symptomatic heart failure with recent decompensation requiring hospitalization or New York Heart Association (NYHA) class IV heart failure and in patients with AF who will not or cannot be cardioverted into normal sinus rhythm. ${ }^{86}$

The PALLAS study, a trial assessing potential cardiovascular outcomes in patients with permanent $\mathrm{AF}$, was prematurely terminated due to increased adverse cardiovascular events in the dronedarone arm. ${ }^{92}$ There were 25 deaths in the dronedarone group (21 from cardiovascular causes) and 13 in the placebo group (10 from cardiovascular causes) $(P=0.046)$. The coprimary outcome, a composite of stroke, myocardial infarction, systemic embolism, or death from cardiovascular causes, occurred in 43 patients receiving dronedarone and 19 patients receiving placebo $(P=0.002)$. These data indicate that dronedarone should not be used in patients with permanent AF who are at risk for major vascular events. ${ }^{92}$

There have been several postmarketing reports of hepatocellular liver injury and hepatic failure in patients receiving dronedarone, including two reports of acute hepatic failure that required transplantation and new-onset or worsening heart failure. ${ }^{93,94}$ Obtaining periodic hepatic serum enzymes, especially during the first 6 months of treatment with dronedarone, is recommended ${ }^{86}$ Postmarketing cases of increased INR with or without bleeding events have also been reported in patients on warfarin initiated on dronedarone ${ }^{86,95}$ Postmarketing cases of interstitial lung disease including pneumonitis and pulmonary fibrosis have also been reported. ${ }^{86}$ Exposure to dabigatran is also higher when it is administered with dronedarone than when it is administered alone. ${ }^{86}$

The US FDA recently completed a safety review of dronedarone based on data from the PALLAS and ATHENA trials.
This review showed that dronedarone increased the risk of serious cardiovascular events, including death, when used by patients with permanent $\mathrm{AF}^{96}$ The prescribing information for dronedarone has been revised to include recommendations from the FDA regarding the use of dronedarone to manage the potential serious cardiovascular risks with the drug. ${ }^{86,96}$ These recommendations include: dronedarone should not be used in patients with AF who cannot or will not be converted into normal sinus rhythm (permanent AF); heart rate should be monitored by electrocardiogram at least once every 3 months, and if the patient is in $\mathrm{AF}$, dronedarone should be stopped or, if clinically indicated, the patient should be cardioverted; dronedarone is indicated to reduce hospitalization for AF in patients in sinus rhythm with a history of nonpermanent $\mathrm{AF}$ (known as paroxysmal or persistent $\mathrm{AF}$ ); and patients taking dronedarone should receive appropriate antithrombotic therapy. ${ }^{86,96}$

\section{Vernakalant}

Intravenous vernakalant, a sodium and potassium channel blocker with atrial-selective action, is approved in the European Union, Iceland, and Norway for the rapid conversion of recent-onset $\mathrm{AF}$ to sinus rhythm in adult nonsurgery patients with $\mathrm{AF}$ of $\leq 7$ days duration and for adult post-cardiac surgery patients with $\mathrm{AF}$ of $\leq 3$ days duration. ${ }^{97}$ In the AVRO study, intravenous vernakalant was more effective than amiodarone for acute conversion of recent-onset AF. ${ }^{98}$ For the oral formulation, early phase II studies demonstrated that oral vernakalant successfully maintained sinus rhythm compared with placebo, and no proarrhythmias relating to vernakalant have been reported to date. ${ }^{99}$ There were also no serious adverse events related to vernakalant in phase II trials. ${ }^{100}$ Vernakalant was found to be an effective agent for conversion to normal sinus rhythm in patients with recent-onset $\mathrm{AF} .{ }^{99}$ In a review of six early-phase clinical trials, vernakalant rapidly and effectively terminated recentonset $\mathrm{AF}$ and was found to be well tolerated and efficacious at $\mathrm{AF}$ conversion in patients with postoperative AF. ${ }^{99}$ Further studies are warranted to better define the role of vernakalant in the management of AF in order to determine whether its benefits translate into a decreased cost burden.

\section{Catheter ablation}

For AF patients whose symptoms are not well controlled with pharmacologic therapy, catheter ablation is an increasingly used treatment option. According to the 2011 ACCF/AHA/HRS guideline update, catheter ablation may be useful to maintain sinus rhythm in selected patients 
with significantly symptomatic, paroxysmal AF who have failed treatment with an antiarrhythmic agent and have normal or mildly dilated left atria, normal or mildly reduced left ventricular function, and no severe pulmonary disease (class I recommendation upgraded from class IIa, but remaining a class IIa recommendation in both Europe and Canada); to treat symptomatic persistent AF (class IIa recommendation); and to treat symptomatic paroxysmal AF in patients with significant left atrial dilatation or with significant left ventricular dysfunction (class $\mathrm{IIb}$ recommendation). ${ }^{70}$ Recent studies have reported that catheter ablation successfully treats paroxysmal AF in $>80 \%$ of cases and persistent AF in $>70 \%$ of cases. ${ }^{101}$ However, catheter ablation is associated with major complications (reported in about $6 \%$ of procedures) such as pulmonary vein stenosis, thromboembolism, atrioesophageal fistula, and left atrial flutter. ${ }^{19,102}$

The cost-effectiveness of catheter ablation is difficult to determine due to a number of factors, including differences in the experience levels of centers, use of technology, and rates of reimbursement, which affect cost calculations. ${ }^{101}$ Studies evaluating the cost-effectiveness of AF ablation compared with rhythm control or antiarrhythmic agents have shown that ablation treatment results in improved quality-adjusted life expectancy, but at a higher cost. ${ }^{103-105}$

\section{Conclusion}

Recent data present a compelling picture of the burden of AF on the US health care system and society. As the US population ages and the prevalence of AF increases, it is clear that AF management strategies need to be optimal. Suboptimal management of AF places patients at risk for AF-associated stroke, the most costly AF-associated event. Numerous studies demonstrate the efficacy of anticoagulation in reducing the risk of AF-related embolic events and preventing hospitalizations, but efficacy is compromised by inadequate and suboptimal treatment patterns. Therapeutic strategies such as rate control, rhythm control, and anticoagulation provide cost-effective means to optimally manage the patient with AF, as do treatment options such as new antiarrhythmic agents or catheter ablation. Given that nearly $75 \%$ of the total costs associated with AF are attributed to direct and indirect hospitalization costs, ${ }^{15}$ clinical strategies that can reduce AF-related hospitalizations may optimize care by improving clinical outcomes and reducing costs. Further research is necessary to compare new antiarrhythmic agents with existing therapies to assess clinical and economic differences in real-world settings.

\section{Acknowledgments/Disclosure}

Editorial support for this article was provided by Vrinda Mahajan, PharmD, of Peloton Advantage, LLC. Editorial support for this article was funded by sanofi-aventis US. The opinions expressed in the current article are those of the author. The author received no honoraria or other form of financial support related to the development of this manuscript.

\section{References}

1. Bajpai A, Savelieva I, Camm AJ. Epidemiology and economic burden of atrial fibrillation. Touch Briefings. 2007:14-17.

2. Dorian P, Mangat I, Pinter A, Korley V. The burden of atrial fibrillation: should we abandon antiarrhythmic drug therapy? J Cardiovasc Pharmacol Ther. 2004;9(4):257-262.

3. Naccarelli GV, Varker H, Lin J, Schulman KL. Increasing prevalence of atrial fibrillation and flutter in the United States. Am J Cardiol. 2009; 104(11):1534-1539.

4. Wattigney WA, Mensah GA, Croft JB. Increasing trends in hospitalization for atrial fibrillation in the United States, 1985 through 1999: implications for primary prevention. Circulation. 2003;108(6):711-716.

5. Bialy D. Hospitalization for arrhythmias in the United States: Importance of atrial fibrillation [abstract 716-714]. J Am Coll Cardiol. 1992;19(3):41A

6. Wyse DG, Gersh BJ. Atrial fibrillation: a perspective: thinking inside and outside the box. Circulation. 2004;109(25):3089-3095.

7. Chatap G, Giraud K, Vincent JP. Atrial fibrillation in the elderly: facts and management. Drugs Aging. 2002;19(11):819-846.

8. Hagens VE, Ranchor AV, Van Sonderen E, et al. Effect of rate or rhythm control on quality of life in persistent atrial fibrillation. Results from the Rate Control Versus Electrical Cardioversion (RACE) Study. J Am Coll Cardiol. 2004;43(2):241-247.

9. Dorian P, Jung W, Newman D, et al. The impairment of health-related quality of life in patients with intermittent atrial fibrillation: implications for the assessment of investigational therapy. J Am Coll Cardiol. 2000; 36(4):1303-1309.

10. Paquette M, Roy D, Talajic M, et al. Role of gender and personality on quality-of-life impairment in intermittent atrial fibrillation. $\mathrm{Am} \mathrm{J}$ Cardiol. 2000;86(7):764-768.

11. Kannel WB, Abbott RD, Savage DD, McNamara PM. Epidemiologic features of chronic atrial fibrillation: the Framingham study. $N$ Engl $J$ Med. 1982;306(17):1018-1022.

12. Wattigney WA, Mensah GA, Croft JB. Increased atrial fibrillation mortality: United States, 1980-1998. Am J Epidemiol. 2002;155(9): 819-826.

13. Atrial fibrillation as a contributing cause of death and Medicare hospitalization - United States, 1999. MMWR Morb Mortal Wkly Rep. 2003;52(7):128, 130-128, 131.

14. Singh SN, Tang XC, Singh BN, et al. Quality of life and exercise performance in patients in sinus rhythm versus persistent atrial fibrillation: a Veterans Affairs Cooperative Studies Program Substudy. J Am Coll Cardiol. 2006;48(4):721-730.

15. Coyne KS, Paramore C, Grandy S, Mercader M, Reynolds M, Zimetbaum P. Assessing the direct costs of treating nonvalvular atrial fibrillation in the United States. Value Health. 2006;9(5):348-356.

16. Wu EQ, Birnbaum HG, Mareva M, et al. Economic burden and co-morbidities of atrial fibrillation in a privately insured population. Curr Med Res Opin. 2005;21(10):1693-1699.

17. Lee WC, Lamas GA, Balu S, Spalding J, Wang Q, Pashos CL. Direct treatment cost of atrial fibrillation in the elderly American population: a Medicare perspective. J Med Econ. 2008;11(2):281-298.

18. Anis RR. Role of angiotensin-converting enzyme inhibitors and angiotensin receptor blockers in the management of atrial fibrillation. Exp Clin Cardiol. 2009;14(1):e1-e7. 
19. Fuster V, Ryden LE, Cannom DS, et al. 2011ACCF/AHA/HRS Focused Updates Incorporated Into the ACC/AHA/ESC 2006 Guidelines for the Management of Patients With Atrial Fibrillation A Report of the American College of Cardiology Foundation/American Heart Association Task Force on Practice Guidelines Developed in partnership with the European Society of Cardiology and in collaboration with the European Heart Rhythm Association and the Heart Rhythm Society. J Am Coll Cardiol. 2011;57(11):e101-e198.

20. Teng MP, Catherwood LE, Melby DP. Cost effectiveness of therapies for atrial fibrillation. A review. Pharmacoeconomics. 2000;18(4): $317-333$.

21. Wyse DG, Waldo AL, DiMarco JP, et al. A comparison of rate control and rhythm control in patients with atrial fibrillation. $N$ Engl J Med. 2002;347(23):1825-1833.

22. Bushnell CD, Matchar DB. Pharmacoeconomics of atrial fibrillation and stroke prevention. Am J Manag Care. 2004;10(Suppl 3):S66-S71.

23. Gage BF, Waterman AD, Shannon W, Boechler M, Rich MW, Radford MJ. Validation of clinical classification schemes for predicting stroke: results from the National Registry of Atrial Fibrillation. JAMA. 2001;285(22):2864-2870.

24. Ishak KJ, Proskorovsky I, Guo S, Lin J. Persistence with antiarrhythmics and the impact on atrial fibrillation-related outcomes. Am J Pharm Benefits. 2009;1(4):193-200.

25. Naccarelli GV, Dell'Orfano JT, Wolbrette DL, Patel HM, Luck JC. Cost-effective management of acute atrial fibrillation: role of rate control, spontaneous conversion, medical and direct current cardioversion, transesophageal echocardiography, and antiembolic therapy. Am J Cardiol. 2000;85(10A):36D-45D.

26. Kim MH, Johnston SS, Chu BC, Dalal MR, Schulman KL. Estimation of total incremental health care costs in patients with atrial fibrillation in the United States. Circ Cardiovasc Qual Outcomes. 2011;4(3):313-320.

27. Kim MH, Lin J, Hussein M, Battleman D. Incidence and temporal pattern of hospital readmissions for patients with atrial fibrillation. Curr Med Res Opin. 2009;25(5):1215-1220.

28. Kim MH, Lin J, Hussein M, Kreilick C, Battleman D. Cost of atrial fibrillation in United States managed care organizations. $A d v$ Ther. 2009;26(9):1-11.

29. Patel PP, Johnston SJ, Lin J, Schulman KL, Naccarelli GV. Cost burden of hospitalization and mortality in United States atrial fibrillation/flutter patients [abstract PO03-53]. Presented at: Heart Rhythm 2009; May 13-16, 2009; Boston, MA.

30. Kim MH, Klingman D, Lin J, Battleman DS. Patterns and predictors of discontinuation of rhythm-control drug therapy in patients with newly diagnosed atrial fibrillation. Pharmacotherapy. 2009;29(12): $1417-1426$.

31. Kim MH, Klingman D, Lin J, Pathak P, Battleman DS. Cost of hospital admission for antiarrhythmic drug initiation in atrial fibrillation. Ann Pharmacother. 2009;43(5):840-848.

32. Berlex Laboratories. Betapace [package insert]. Wayne, NJ: Berlex Laboratories, Inc; 2010.

33. Pfizer. Tikosyn [package insert]. New York, NY: Pfizer Labs; 2006.

34. Kim MH, Lin J, Hussein M, Battleman D. Incidence and economic burden of suspected adverse events and adverse event monitoring during AF therapy. Curr Med Res Opin. 2009;25(12):3037-3047.

35. World Health Organization. Shaping the Future. The World Health Report 2003. Geneva, Switzerland: World Health Organization; 2003: $1-204$.

36. Wolf PA, Abbott RD, Kannel WB. Atrial fibrillation as an independent risk factor for stroke: the Framingham Study. Stroke. 1991;22(8): 983-988.

37. The Atrial Fibrillation Investigators. Risk factors for stroke and efficacy of antithrombotic therapy in atrial fibrillation. Analysis of pooled data from five randomized controlled trials. Arch Intern Med. 1994;154(13): 1449-1457.

38. Szucs TD, Bramkamp M. Pharmacoeconomics of anticoagulation therapy for stroke prevention in atrial fibrillation: a review. J Thromb Haemost. 2006;4(6):1180-1185.
39. Ryder KM, Benjamin EJ. Epidemiology and significance of atrial fibrillation. Am J Cardiol. 1999;84(9A):131R-138R.

40. Miller PS, Andersson FL, Kalra L. Are cost benefits of anticoagulation for stroke prevention in atrial fibrillation underestimated? Stroke. 2005; 36(2):360-366.

41. Dulli DA, Stanko H, Levine RL. Atrial fibrillation is associated with severe acute ischemic stroke. Neuroepidemiology. 2003;22(2): $118-123$.

42. Boccuzzi SJ, Martin J, Stephenson J, et al. Retrospective study of total healthcare costs associated with chronic nonvalvular atrial fibrillation and the occurrence of a first transient ischemic attack, stroke or major bleed. Curr Med Res Opin. 2009;25(12):2853-2864.

43. Caro JJ. An economic model of stroke in atrial fibrillation: the cost of suboptimal oral anticoagulation. Am J Manag Care. 2004;10(Suppl 14):S451-S458.

44. Ezekowitz MD, Falk RH. The increasing need for anticoagulant therapy to prevent stroke in patients with atrial fibrillation. Mayo Clin Proc. 2004;79(7):904-913.

45. Wittkowsky AK. Effective anticoagulation therapy: defining the gap between clinical studies and clinical practice. Am J Manag Care. 2004; 10(Suppl 10):S297-S306.

46. Thosani AJ, Xiong Y, Lin J, Kothawala P, Zimetbaum PJ. Are atrial fibrillation patients receiving anticoagulation in accordance with their stroke risk? [abstract PO06-60]. Presented at: Heart Rhythm 2009; May 13-16, 2009; Boston, MA.

47. Damaske DL, Baird RW. Development and implementation of a pharmacist-managed inpatient warfarin protocol. Proc (Bayl Univ Med Cent). 2005;18(4):397-400.

48. NYSED.gov. Practice Alerts and Guidelines: Coumadin (Warfarin) Managed Dosing by Nurses. June 25, 2009. New York State Education Department Office of the Professions. Available from: http://www.op.nysed.gov/prof/nurse/nurse-coumadin.htm. Accessed December 12, 2011.

49. Chiquette E, Amato MG, Bussey HI. Comparison of an anticoagulation clinic with usual medical care: anticoagulation control, patient outcomes, and health care costs. Arch Intern Med. 1998;158(15):1641-1647.

50. Scott PA, Pancioli AM, Davis LA, Frederiksen SM, Eckman J. Prevalence of atrial fibrillation and antithrombotic prophylaxis in emergency department patients. Stroke. 2002;33(11):2664-2669.

51. McCormick D, Gurwitz JH, Goldberg RJ, et al. Prevalence and quality of warfarin use for patients with atrial fibrillation in the long-term care setting. Arch Intern Med. 2001;161(20):2458-2463.

52. Samsa GP, Matchar DB, Goldstein LB, et al. Quality of anticoagulation management among patients with atrial fibrillation: results of a review of medical records from 2 communities. Arch Intern Med. 2000;160(7): 967-973.

53. Sorensen SV, Dewilde S, Singer DE, Goldhaber SZ, Monz BU, Plumb JM. Cost-effectiveness of warfarin: trial versus "real-world" stroke prevention in atrial fibrillation. Am Heart J. 2009;157(6):1064-1073.

54. Singer DE, Albers GW, Dalen JE, Go AS, Halperin JL, Manning WJ. Antithrombotic therapy in atrial fibrillation: the Seventh ACCP Conference on Antithrombotic and Thrombolytic Therapy. Chest. 2004; 126(Suppl 3):429S-456S

55. Albers GW, Diener HC, Frison L, et al. Ximelagatran vs warfarin for stroke prevention in patients with nonvalvular atrial fibrillation: a randomized trial. JAMA. 2005;293(6):690-698.

56. Boulanger L, Kim J, Friedman M, Hauch O, Foster T, Menzin J. Patterns of use of antithrombotic therapy and quality of anticoagulation among patients with non-valvular atrial fibrillation in clinical practice. Int $J$ Clin Pract. 2006;60(3):258-264.

57. Sullivan PW, Arant TW, Ellis SL, Ulrich H. The cost effectiveness of anticoagulation management services for patients with atrial fibrillation and at high risk of stroke in the US. Pharmacoeconomics. 2006;24(10): 1021-1033.

58. Ghate SR, Biskupiak J, Ye X, Kwong WJ, Brixner DI. All-cause and bleeding-related health care costs in warfarin-treated patients with atrial fibrillation. J Manag Care Pharm. 2011;17(9):672-684. 
59. Baetz BE, Spinler SA. Dabigatran etexilate: an oral direct thrombin inhibitor for prophylaxis and treatment of thromboembolic diseases. Pharmacotherapy. 2008;28(11):1354-1373.

60. Franchini M, Mannucci PM. A new era for anticoagulants. Eur J Intern Med. 2009;20(6):562-568.

61. De Caterina R, Kristensen SD, Renda G. New anticoagulants for atrial fibrillation. J Cardiovasc Med (Hagerstown). 2009;10(6):446-453.

62. Samama MM, Gerotziafas GT. Newer anticoagulants in 2009. JThromb Thrombolysis. 2010;29(1):92-104.

63. Patel MR, Mahaffey KW, Garg J, et al. Rivaroxaban versus warfarin in nonvalvular atrial fibrillation. $N$ Engl J Med. 2011;365(10):883-891.

64. US Food and Drug Administration. FDA approves Xarelto to prevent stroke in people with common type of abnormal heart rhythm [press release]. November 4, 2011. Available from: http://www.fda.gov/News Events/Newsroom/PressAnnouncements/ucm278646.htm. Accessed November 7, 2011

65. Connolly SJ, Eikelboom J, Joyner C, et al. Apixaban in patients with atrial fibrillation. $N$ Engl J Med. 2011;364(9):806-817.

66. Granger CB, Alexander JH, McMurray JJ, et al. Apixaban versus warfarin in patients with atrial fibrillation. NEngl J Med. 2011;365(11): 981-992.

67. US Food and Drug Administration. FDA approves Pradaxa to prevent stroke in people with atrial fibrillation. October 19, 2010. Available from: http://www.fda.gov/NewsEvents/Newsroom/PressAnnouncements/ ucm230241.htm. Accessed July 13, 2011.

68. Ezekowitz MD, Connolly S, Parekh A, et al. Rationale and design of RE-LY: randomized evaluation of long-term anticoagulant therapy, warfarin, compared with dabigatran. Am Heart J. 2009;157(5): $805-810$

69. Connolly SJ, Ezekowitz MD, Yusuf S, et al. Dabigatran versus warfarin in patients with atrial fibrillation. $N$ Engl J Med. 2009;361(12): 1139-1151.

70. Wann LS, Curtis AB, January CT, et al. 2011 ACCF/AHA/HRS focused update on the management of patients with atrial fibrillation (updating the 2006 guideline): a report of the American College of Cardiology Foundation/American Heart Association Task Force on practice guidelines. Circulation. 2011;123:104-123.

71. Reynolds MR, Essebag V, Zimetbaum P, Cohen DJ. Healthcare resource utilization and costs associated with recurrent episodes of atrial fibrillation: the FRACTAL registry. J Cardiovasc Electrophysiol. 2007;18(6):628-633.

72. Gronefeld GC, Lilienthal J, Kuck KH, Hohnloser SH. Impact of rate versus rhythm control on quality of life in patients with persistent atria fibrillation. Results from a prospective randomized study. Eur Heart J. 2003;24(15):1430-1436.

73. Carlsson J, Miketic S, Windeler J, et al. Randomized trial of rate-control versus rhythm-control in persistent atrial fibrillation: the Strategies of Treatment of Atrial Fibrillation (STAF) study. J Am Coll Cardiol. 2003 41(10):1690-1696.

74. van Gelder I, Hagens VE, Bosker HA, et al. A comparison of rate control and rhythm control in patients with recurrent persistent atrial fibrillation. N Engl J Med. 2002;347(23):1834-1840.

75. Roy D, Talajic M, Nattel S, et al. Rhythm control versus rate control for atrial fibrillation and heart failure. $N$ Engl J Med. 2008;358(25): 2667-2677.

76. Marshall DA, Levy AR, Vidaillet H, et al. Cost-effectiveness of rhythm versus rate control in atrial fibrillation. Ann Intern Med. 2004;141(9): 653-661.

77. Corley SD, Epstein AE, DiMarco JP, et al. Relationships between sinus rhythm, treatment, and survival in the Atrial Fibrillation Follow-Up Investigation of Rhythm Management (AFFIRM) Study. Circulation. 2004;109(12):1509-1513.

78. Freeman JV, Zhu RP, Owens DK, et al. Cost-effectiveness of dabigatran compared with warfarin for stroke prevention in atrial fibrillation. Ann Intern Med. 2011;154(1):1-11.

79. Shah SV, Gage BF. Cost-effectiveness of dabigatran for stroke prophylaxis in atrial fibrillation. Circulation. 2011;123(22):2562-2570.
80. Kamel H, Johnston SC, Easton JD, Kim AS. Cost-effectiveness of dabigatran compared with warfarin for stroke prevention in patients with atrial fibrillation and prior stroke or transient ischemic attack. Stroke. 2012;43(3):881-883.

81. Pink J, Lane S, Pirmohamed M, Hughes DA. Dabigatran etexilate versus warfarin in management of non-valvular atrial fibrillation in UK context: quantitative benefit-harm and economic analyses. BMJ. 2011; 343:d6333.

82. Hohnloser SH, Crijns HJ, van Eickels M, et al. Effect of dronedarone on cardiovascular events in atrial fibrillation. N Engl J Med. 2009;360(7): 668-678.

83. Naccarelli GV, Johnston SS, Lin J, Patel PP, Schulman KL. Cost burden of cardiovascular hospitalization and mortality in ATHENA-like patients with atrial fibrillation/atrial flutter in the United States. Clin Cardiol. 2010;33(5):270-279.

84. Ehrlich JR, Nattel S. Atrial-selective pharmacological therapy for atrial fibrillation: hype or hope? Curr Opin Cardiol. 2009;24(1):50-55.

85. Bajpai A, Savelieva I, Camm AJ. Treatment of atrial fibrillation. $\mathrm{Br}$ Med Bull. 2008;88(1):75-94.

86. sanofi-aventis. Multaq [package insert]. Bridgewater, NJ: sanofi-aventis US LLC; 2012.

87. Connolly SJ, Crijns HJ, Torp-Pedersen C, et al. Analysis of stroke in ATHENA: a placebo-controlled, double-blind, parallel-arm trial to assess the efficacy of dronedarone $400 \mathrm{mg}$ BID for the prevention of cardiovascular hospitalization or death from any cause in patients with atrial fibrillation/atrial flutter. Circulation. 2009;120:1174-1180.

88. Davy JM, Herold M, Hoglund C, et al. Dronedarone for the control of ventricular rate in permanent atrial fibrillation: the Efficacy and safety of dRonedArone for The cOntrol of ventricular rate during atrial fibrillation (ERATO) study. Am Heart J. 2008;156(3):527-529.

89. Singh BN, Connolly SJ, Crijns HJ, et al. Dronedarone for maintenance of sinus rhythm in atrial fibrillation or flutter. N Engl J Med. 2007;357(10): 987-999.

90. Touboul P, Brugada J, Capucci A, Crijns HJ, Edvardsson N, Hohnloser SH. Dronedarone for prevention of atrial fibrillation: a dose-ranging study. Eur Heart J. 2003;24(16):1481-1487.

91. Kober L, Torp-Pedersen C, McMurray JJ, et al. Increased mortality after dronedarone therapy for severe heart failure. N Engl J Med. 2008; 358(25):2678-2687.

92. Connolly SJ, Camm AJ, Halperin JL, et al. Dronedarone in high-risk permanent atrial fibrillation. $N$ Engl J Med. 2011;365(24):2268-2276.

93. US Food and Drug Administration. FDA Drug Safety Communication: Severe liver injury associated with the use of dronedarone (marketed as Multaq). January 14, 2011. Available from: http:/www.fda.gov/Drugs/ DrugSafety/ucm240011.htm. Accessed July 13, 2011.

94. US Food and Drug Administration. Potential signals of serious risks/new safety information identified by the adverse event reporting system (AERS) between July-September 2010. January 11,2011. Available from: http://www. fda.gov/Drugs/GuidanceComplianceRegulatoryInformation/Surveillance/ AdverseDrugEffects/ucm237585.htm. Accessed March 21, 2011.

95. QuarterWatch. QuarterWatch: 2010 Quarter 1. Monitoring MedWatch Reports. Signals for acetaminophen, dronedarone and botulinum toxin products [executive summary]. November 4, 2010. Available from: http://freepdfhosting.com/078147c86d.pdf. Accessed March 21, 2011.

96. US Food and Drug Administration. FDA Drug Safety Communication: review update of multaq (dronedarone) and increased risk of death and serious cardiovascular adverse events. December 21, 2011. Available from: http://www.fda.gov/Drugs/DrugSafety/ucm283933. htm. Accessed January 3, 2012.

97. Merck. Merck to Acquire Rights to Vernakalant i.v. in Canada, Mexico and the United States from Astellas. Jul 26, 2011. Available from: http://www.merck.com/newsroom/news-release-archive/research-anddevelopment/2011_0726.html. Accessed November 1, 2011.

98. Camm AJ, Capucci A, Hohnloser SH, et al. A randomized activecontrolled study comparing the efficacy and safety of vernakalant to amiodarone in recent-onset atrial fibrillation. J Am Coll Cardiol. 2011; 57(3):313-321. 
99. Cheng JW. Vernakalant in the management of atrial fibrillation. Ann Pharmacother. 2008;42(4):533-542.

100. Ehrlich JR, Nattel S. Novel approaches for pharmacological management of atrial fibrillation. Drugs. 2009;69(7):757-774.

101. Nault I, Miyazaki S, Forclaz A, et al. Drugs vs ablation for the treatment of atrial fibrillation: the evidence supporting catheter ablation. Eur Heart J. 2010;31(9): 1046-1054.

102. Cappato R, Calkins H, Chen SA, et al. Worldwide survey on the methods, efficacy, and safety of catheter ablation for human atrial fibrillation. Circulation. 2005;111(9):1100-1105.
103. Chan PS, Vijan S, Morady F, Oral H. Cost-effectiveness of radio frequency catheter ablation for atrial fibrillation. $J \mathrm{Am}$ Coll Cardiol. 2006;47(12):2513-2520.

104. Reynolds MR, Zimetbaum P, Josephson ME, Ellis E, Danilov T, Cohen DJ. Cost-effectiveness of radiofrequency catheter ablation compared with antiarrhythmic drug therapy for paroxysmal atrial fibrillation. Circ Arrhythm Electrophysiol. 2009;2(4):362-369.

105. Rodgers M, McKenna C, Palmer S, et al. Curative catheter ablation in atrial fibrillation and typical atrial flutter: systematic review and economic evaluation. Health Technol Assess. 2008;12(34):iii-xiii, 1.

\section{Publish your work in this journal}

ClinicoEconomics \& Outcomes Research is an international, peerreviewed open-access journal focusing on Health Technology Assessment, Pharmacoeconomics and Outcomes Research in the areas of diagnosis, medical devices, and clinical, surgical and pharmacological intervention. The economic impact of health policy and health systems organization also constitute important areas of coverage. The manuscript management system is completely online and includes a very quick and fair peer-review system, which is all easy to use. Visit http://www.dovepress.com/testimonials.php to read real quotes from published authors.

Submit your manuscript here: http://www.dovepress.com/clinicoeconomics-and-outcomes-research-journal 